\title{
NARRATIVA TRANSMÍDIA: \\ UMA ANÁLISE SEMIÓTICA DA CAMPANHA PUBLICITÁRIA THE EXPERIENCE INSIDE
}

\author{
TRANSMEDIA NARRATIVE: \\ A SEMIOTIC ANALYSIS OF THE ADVERTISING CAMPAIGN THE EXPERIENCE \\ INSIDE
}

Patrícia Margarida Farias Coelho
Universidade Metodista de São Paulo (UMESP) e Universidade Ibirapuera (UNIB)
patriciafariascoelho@gmail.com

Marcos Rogério Martins Costa

Faculdade Unificada do Estado de São Paulo (FAUESP)

marcosrmcosta15@gmail.com

Resumo: A transmídia consiste na veiculação em distintas plataformas de mídias e dispositivos móveis de expansões narrativas que são (re)criadas a partir de uma narrativa matriz e de uma mídia regente em processos de traduções intergenéricas e/ou intersemióticas. Nossa proposta é a de fazer uma análise semiótica do plano do conteúdo de uma narrativa transmídia, baseada numa perspectiva interdisciplinar entre, de um lado, a semiótica discursiva (GREIMAS; COURTÉS, 2008), e de outro, as novas mídias (JENKINS, 2009). Para tanto, escolhemos como objeto de estudo a campanha transmidiática The experience inside, lançada em 2011 por Toshiba e Intel, por ser uma das pioneiras no uso da transmídia como estratégia publicitária para captação de recursos e de consumidores. Com base no filme socialinterativo produzido durante a campanha, este estudo faz uma análise discursiva dessa narrativa transmídia.

Palavras-chave: Transmídia. Semiótica discursiva. Novas mídias. Comunicação.

Abstract: Transmedia narrative: a semiotic analysis of the advertising campaign the Experience inside - Transmedia consists of the placement on different platforms of media and mobile devices of narrative expansions that are (re) created from a matrix narrative and a regent media in processes of intergeneric and / or intersemiotic translations. Our proposal is to make a semiotic analysis of the content plan of a transmedia narrative, based on an interdisciplinary perspective between, on the one hand, the discursive semiotics (GREIMAS and COURTÉS, 2008), and on the other hand, the new media (JENKINS, 2009). To that end, we chose as a study object the transmission experience campaign, The Experience Inside, launched in 2011 by Toshiba and Intel, as one of the pioneers in the use of transmigration as an advertising strategy for attracting resources and consumers. Based on the socialinteractive film produced during the campaign, this study makes a discursive analysis of this transmedia narrative.

Keywords: Transmission. Discursive semiotics. New media. Communication.

\section{Introdução}

Atualmente nos relacionamos com as mídias de uma forma absolutamente diferente de como ocorria no século passado. Houve um avanço extraordinário das mídias digitais frente às mídias tradicionais, e esse processo fez com que se 
desenvolvessem conceitos e práticas distintas em nossa sociedade. ${ }^{1}$ Um dos conceitos emergentes dessa cultura digital é o de transmídia, proposto por Jenkins (2009). A narrativa transmídia define-se como "histórias que se desenrolam em múltiplas plataformas de mídia, cada uma delas contribuindo de forma distinta para nossa compreensão do universo [de significação]" (JENKINS, 2009, p. 384). ${ }^{2}$

Em termos discursivos, conforme Camara (2014, p. 171), a transmídia caracteriza-se pela veiculação em distintas plataformas de mídias e dispositivos móveis de expansões narrativas, as quais são "criadas a partir de uma narrativa matriz e de uma mídia regente em processos de traduções intergenéricas e intersemióticas". ${ }^{3}$ Em nossa concepção, na transmidiação, as traduções podem ocorrer tanto simultaneamente (e... e...) quanto alternadamente (ou... ou...). Consequentemente, os processos de expansão textuais e discursivos podem ser criados ou recriados, pois estão em desenvolvimento.

Compreendendo a crescente difusão desse tipo de produção midiática, propomos fazer uma análise semiótica do plano do conteúdo de uma narrativa transmídia. Para tanto, baseamo-nos numa perspectiva interdisciplinar entre, de um lado, a semiótica discursiva (GREIMAS; COURTÉS, 2008), e de outro, as novas mídias (JENKINS, 2009). Ressalvamos que respeitamos a epistemologia de cada uma dessas áreas do conhecimento. ${ }^{4}$

\footnotetext{
${ }^{1}$ Nesta pesquisa, o termo mídia é entendido como um veículo de um determinado sistema de comunicação social, conforme Jenkins (2009). Considerando os setores tradicionais, existem as mídias tradicionais, como: rádio, TV, jornal, revista, dentre outros. A partir do avanço tecnológico, as mídias digitais se consolidaram, principalmente com a expansão da internet.

${ }^{2}$ De acordo com Jenkins (2009, p. 145), "o conceito de narrativa transmídia entrou para o debate público pela primeira vez em 1999, enquanto audiências e críticos tentavam entender o sucesso fenomenal de $A$ bruxa de Blair (1999), um filme independente de baixo orçamento que se tornou um negócio imensamente rendoso. [...] A bruxa de Blair havia conquistado uma legião de seguidores na web mais de um ano antes de chegar a qualquer sala de cinema".

3 A semiótica discursiva entende tradução como "a atividade cognitiva que opera a passagem de um enunciado dado em outro considerado como equivalente" (GREIMAS; COURTÉS, 2008, p. 508). Alertamos que tradução alguma é, em sua totalidade, equivalente, conforme não são os sinônimos. Por isso, a expressão tradução intersemiótica designa, aqui, a ressignificação de um determinado sistema de signos para outro sistema semiótico; já o conceito de tradução intergenérica se refere à ressignificação de um gênero discursivo por meio de outro. Por exemplo, temos um romance que se traduz intersemioticamente em forma de filme que, depois, pode se expandir em um jogo; ou, ainda, esse mesmo romance pode ser traduzido intergenericamente em forma de um conto.

${ }^{4}$ Partimos do seguinte critério teórico-metodológico para realizar esse estudo interdisciplinar: "a interdisciplinaridade pressupõe uma convergência, uma complementaridade, o que significa, de um lado, a transferência de conceitos teóricos e de metodologias e, de outro, a combinação de áreas" (FIORIN, 2008a, p. 38).
} 
O intercâmbio de conceitos entre a semiótica francesa e a comunicação não é recente. Resgatando os percursos da História, destacamos que Algirdas Julien Greimas (1917-1992), fundador da semiótica francesa, teve também um papel importante para a consolidação das ciências da informação e comunicação no contexto francês, que até hoje é pouco conhecido e, por isso mesmo, insuficientemente divulgado. Como pesquisador reconhecido, ele foi um dos treze membros selecionados para compor o comitê francês que tinha como objetivo reconhecer a área de estudos da ciência da informação e comunicação no Ministério da Educação. Cabe salientar ainda que o mestre lituano participou, em outubro de 1970, na cidade de Milão, Itália, do Congresso Nacional do Instituto Gemelli, que tinha como tema "Estado e tendências atuais da pesquisa em comunicação de massa". Essa discussão foi tão frutífera que resultou no livro Semiótica e ciências sociais, publicado em 1976, com tradução brasileira em 1981. E durante todo o desenvolvimento do projeto semiótico, a comunicação e seus campos de pertinência foram sendo analisados pelos semioticistas: ora como objetos de estudo, ora como procedimentos teórico-metodológicos.

Este estudo acompanha o movimento do projeto semiótico pretendendo, também, investigar o plano do conteúdo de uma narrativa transmídia, para, assim, podermos evidenciar alguns dos mecanismos de significação vigentes nesse tipo de produção textual. Para tanto, distinguimos que o conceito de narrativa transmídia, apesar de se relacionar com a noção semiótica de narratividade (GREIMAS; COURTÉS, 2008, p. 328-330), não compartilha da mesma definição terminológica de narrativa na teoria da semiótica greimasiana. A expressão narrativa, a partir da metalinguagem semiótica, designa, em sua mais simples realização, uma passagem de um enunciado de estado anterior a um enunciado de estado posterior, "operado com a ajuda de um fazer (ou um processo)" (GREIMAS; COURTÉS, 2008, p. 327). Logo, narrativa, na teoria semiótica, representa um conceito operatório em uso metalinguístico, e narrativa transmídia constitui, na metalinguagem semiótica, uma semiótica-objeto, uma vez que retrata a manifestação de um sistema de signos. Sendo assim, articulando os dois conceitos, em uma visada semiótica, a narrativa transmídia possui diversos programas narrativos os quais concretizam o fazer dentro do texto. Por isso, semioticamente, em sua totalidade, ela não possui uma narrativa, mas um conjunto de programas narrativos. 
Observando essas diferenças de uso, e o proveitoso encontro entre semiótica e comunicação, escolhemos como objeto de estudo a campanha transmidiática The experience inside, lançada em 2011 por Toshiba e Intel, por serem as pioneiras no uso da transmídia como estratégia publicitária para a captação de recursos e de consumidores. Destacamos que essa transmídia faz parte do projeto Inside, dirigido pela agência publicitária Pereira\&O’Dell, para divulgar as marcas e os produtos de Toshiba e Intel, as quais são grandes multinacionais do ramo da tecnologia e da inovação. Até 2015, quatro campanhas transmidiáticas do projeto foram criadas e desenvolvidas por essa mesma agência: The experience inside (2011), The beauty inside (2012), The power inside (2013) e What lives inside (2015). Ressalvamos que, em 2015, a parceria das marcas patrocinadoras mudou, e também o produto vinculado à publicidade foi alterado. Na campanha What lives inside, a Intel se associou à multinacional Dell, e o produto divulgado não foi mais um computador, como nas outras três; diferentemente, tivemos um tablet como produto principal. ${ }^{5}$

Essa campanha publicitária constitui um exemplo de narrativa transmídia por diversos motivos. O principal deles é ter conseguido articular um processo coordenado de entretenimento publicitário que disseminou sistematicamente elementos integrais de uma narrativa matriz em múltiplos canais midiáticos. Alguns canais que fizeram parte dessa transmídia foram: (i) um site oficial ${ }^{6}$, (ii) uma página no Twitter ${ }^{7}$, (iii) uma página no Facebook $^{8}$ e (iv) um hotsite ${ }^{9}$ - ressaltamos que muitos desses canais já não estão mais disponíveis na internet. O hotsite, por exemplo, foi criado especificamente para divulgar o notebook Toshiba Satellite ${ }^{\circledR}$ P775 com processador Intel Core ${ }^{\circledR}$ i7 ${ }^{\mathrm{TM}}$, produto alvo dessa publicidade transmídia. ${ }^{10} \mathrm{O}$ componente diferencial destacado neste produto pela propaganda oferecia uma conexão à internet não rastreável.

\footnotetext{
${ }^{5}$ Pereira\&O’Dell surgiu de uma parceria entre o brasileiro Paulo Jorge Pereira e o americano Andrew O’Dell, fundada em 2009. Essa agência está associada ao Grupo ABC de Comunicações - o maior conglomerado de comunicação da América Latina e o $18^{\circ}$ maior grupo de comunicação do mundo, segundo o ranking Advertising Age, divulgado em 2014.

${ }^{6}$ Esteve disponível em: http://theinsideexperience.com. Acesso em: 31 de mar. 2019.

${ }^{7}$ Esteve disponível em: @ theinsideexp. Acesso em: 31 de mar. 2019.

${ }^{8}$ Esteve disponível em: facebook.com/theinsideexperience. Acesso em: 31 de mar. 2019.

${ }^{9}$ Esteve disponível em: http://theinsideexperience.com/product. Acesso em: 31 de mar. 2019.

10 De acordo com o Dicionário de Informática e Negócios (2015), hotsite define-se como "uma ferramenta de marketing para internet que consiste em manter um website no ar, por um período de tempo determinado, para promoção de produtos e serviços; composto, em geral, por uma ou quatro páginas".
} 
Essa campanha também se caracteriza por ser um advergame, como explica COELHO (2012). De acordo com essa estudiosa, o advergame é um jogo com intenções publicitárias que visa a jogabilidade e o consumo. Esse tipo de jogo foi incorporado à narrativa transmídia da campanha para estimular a participação dos usuários e fidelizálos às marcas patrocinadoras. Essa foi, portanto, uma via de mão dupla: da campanha para o jogo e do usuário-jogador para ao usuário-consumidor.

A partir do filme social-interativo Inside - A social film experience, dirigido por Daniel John Caruso e lançado em 2011, faremos uma análise do plano do conteúdo dessa campanha publicitária. Ressaltamos que essa produção foi um marco na história da comunicação, pois, além de ter atraído um público-consumidor extraordinário, ela gerou o primeiro filme social-interativo de Hollywood. Para muitos teóricos, esse filme pode ser considerado um exemplo de transcinema, que, conforme Maciel (2010, p. 10) define, é "o cinema situação". Em outros termos, é um tipo de cinema que trabalha com transformações e experimentações. No caso do filme Inside, o conceito se aplica bem, visto que foi produzido com a colaboração e a participação ativa do público, com um roteiro lacunar em que os usuários-consumidores iam construindo a narrativa junto com o diretor Caruso e sua equipe. Eis uma produção bastante peculiar de construção fílmica, pois ela corrobora o sensível e o inteligível nos nativos e imigrantes digitais ${ }^{11}$.

Neste artigo, devido às limitações espaço-temporais, discutiremos apenas as estruturas narrativas, discursivas e fundamentais da campanha The experience inside, principalmente pela construção do filme, não tratando, portanto, das particularidades da produção e da edição das cenas que faremos em estudos ulteriores sobre o plano da expressão dessa campanha publicitária.

Por isso, metodologicamente, dividiremos o plano do conteúdo em três níveis: fundamental, narrativo e discursivo. Com base nesse arcabouço teórico, exploraremos as características das estratégias discursivas e narrativas do corpus selecionado. Compreendendo, dessa maneira, o que o texto diz, como diz e por que diz (BARROS, 2002). Pretendemos, assim, fazer algumas projeções teórico-metodológicas do percurso

\footnotetext{
${ }^{11}$ Para saber mais informações sobre os nativos e os imigrantes digitais, consultar os desdobramentos teóricos que propomos em Coelho, Costa e Mattar (2018).
} 
gerativo do sentido (GREIMAS; COURTÉS, 2008) a partir da análise semiótica do filme social resultante da campanha transmidiática realizada ${ }^{12}$.

Destacamos ainda que diversos estudos nacionais e internacionais recentemente publicados tem apontado a necessidade de se pensar a importância do uso da narrativa transmitida como novas propostas e possibilidades de comunicação (LIMA, MERCADO, VERSUTI, 2017; LEDO, 2015)

\section{Análise semiótica da campanha transmidiática the experience inside}

Nos próximos tópicos, exploraremos os três níveis que constituem o percurso gerativo do sentido dessa campanha. Para isso, utilizaremos como corpus principal o filme social, resultado final da campanha, dirigido por Caruso e lançado em 2011. Fizemos essa escolha, pois o filme retoma, como uma totalidade discursiva, grande parte dos discursos que compõem a tessitura dessa campanha, com maior ou menor grau de presença.

\section{Nível narrativo}

No nível das estruturas narrativas, "representam-se ou estimulam-se, como em um espetáculo, o fazer do homem que transforma o mundo, suas relações com os outros homens, seus valores, aspirações e paixões" (BARROS, 2002, p. 87). Ressaltamos, ainda, que "as estruturas semióticas, ditas narrativas, regem, para nós, as estruturas discursivas" (GREIMAS; COURTÉS, 2008, p. 329), por isso, começamos nossa análise por esse nível intermediário do percurso gerativo do sentido.

Em Inside - A social film experience, a protagonista Christina, uma mulher de cerca de vinte anos, acorda em um quarto escuro. Ao perceber que está encarcerada nesse local, ela tenta fazer um reconhecimento do espaço, mas não consegue, pois não há luminosidade. Ela, então, percebe que existe ali uma mesa com um computador: o notebook Toshiba, com processador Intel, que possui uma conexão à internet não rastreável. Christina, a princípio, utiliza a luz da tela desse equipamento como lanterna. Essa cena inaugura a relação entre o ser humano e a tecnologia dentro da trama fílmica.

O ser humano, no caso, o ator Christina, constitui-se narrativamente como o sujeito da narrativa, e a tecnologia, o computador, como o objeto de valor. Esse objeto

\footnotetext{
${ }^{12}$ Para saber mais sobre a teoria semiótica e os níveis do percurso gerativo do sentido, indicamos a leitura de Barros (2002) e de Coelho, Costa e Fontanari (2015).
} 
de valor participa tanto das modalidades virtualizantes (dever-fazer; querer-fazer), que instauram o sujeito, quanto das modalidades atualizantes (saber-fazer; poder-fazer), que, por sua vez, qualificam o sujeito para a ação. Nessa cena inicial, o computador serviu como objeto de valor de um programa narrativo de uso para conseguir um poder-fazer em um programa narrativo de base, no caso, poder reconhecer o lugar onde estava. Durante toda a narrativa, essa relação entre Christina e o computador se intensifica.

De forma geral, no início da trama, ocorre um programa narrativo de transformação do enunciado de estado inicial $\left(\mathrm{PN}_{1}\right)$. Christina $\left(\mathrm{S}_{1}\right)$ estava em conjunção $(\cap)$ com o objeto de valor liberdade $\left(\mathrm{Ov}_{1}\right)$. Depois do enunciado de transformação, há um segundo enunciado de estado em que $S_{1}$ passa a estar em disjunção $(\cup) \operatorname{com} O v_{1}$. Podemos visualizar essa transformação dos enunciados de estado no seguinte esquema:

$$
\mathrm{PN}_{1}:\left(\mathrm{S}_{\text {[ATOR Christina] }} \cap \mathrm{Ov}_{1 \text { [liberdade }]}\right) \rightarrow\left(\mathrm{S}_{2[\text { ATOR Christina] }} \cup \mathrm{Ov}_{\text {[liberdade }]}\right)
$$

Christina, portanto, sofreu uma espoliação do $\mathrm{Ov}_{1}$ por privação. Além disso, seu antissujeito é desconhecido. Ela, então, utiliza o notebook para pedir socorro. Para isso, vai à sua rede social, alerta seus amigos, parentes e conhecidos. E, a partir daí, forma-se uma rede de contatos que tem como objetivo ajudar a Christina a descobrir onde está sendo mantida e como pode escapar de lá. Os espectadores de sua trama foram, assim, estimulados a se conectarem com a protagonista. Para isso, eles deixaram pistas no Twitter e conselhos no mural do Facebook oficial de Christina. Temos, então, outro programa narrativo de uso no qual $S_{1}$ estava inicialmente em disjunção com a rede de contatos $\left(\mathrm{S}_{2}\right)$ - que cresceu exponencialmente após o apelo de socorro da protagonista $^{13}$ - e, depois, $S_{1}$ passa a estar em conjunção com $S_{2}$.

É importante notar nesse programa narrativo de uso que os espectadores, ao interagirem com Christina e participarem da narrativa como actante $\mathrm{S}_{2}$, tornaram-se atores do enunciado. Eles, portanto, não são mais apenas uma unidade pressuposta ao enunciado, isto é, eles não possuem somente o papel actancial de enunciatário do texto. Agora, eles podem ser também atores do enunciado. Ao participarem da narrativa, eles adquirem um papel sintático. Ao ser discursivizado, tematizado e figurativizado, esses actantes recebem um papel semântico no nível discursivo. A convergência desses dois componentes, sintático e semântico, torna esses espectadores atores do enunciado. Isso

\footnotetext{
${ }^{13}$ Em uma semana, a página do Facebook de Christina atraiu cerca de 20 mil contatos/amigos, segundo dados divulgados por Toshiba e Intel, em 2011.
} 
foi possível porque houve um casting on-line no YouTube, que começou no dia $11 \mathrm{e}$ terminou no dia 20 de julho de 2011. O vídeo vencedor desse casting on-line foi incorporado ao filme, e o nome do espectador vencedor foi incluído nos créditos.

Podemos visualizar a seguir uma página da rede social Facebook nomeada de INSIDE Experience $(\text { Facebook })^{14}$, criada pelos próprios fãs da transmídia, ainda disponível. Temos, assim, em cotejo, uma mídia sendo divulgada e seu desdobramento pelos fãs, o que confirma o caráter transmidiático da campanha, conforme a proposta de Jenkins (2009).

Em relação à elaboração do filme, ele foi realizado com a colaboração da rede de contatos de Christina. Para isso ocorrer, houve uma equipe de edição em que o editor, Josh Bodnar, era o responsável por selecionar e incorporar os posts, vídeos e imagens que melhor se adequassem à narrativa que estava sendo construída. Portanto, embora uma mídia alimente a outra, o enunciador convoca o enunciatário de maneira controlada. Isso ocorre porque o sujeito da enunciação prevê e controla as ações narrativas de modo a fazer-crer (isto é, estabelecer um contrato fiduciário) e a fazerfazer (ou seja, estimular o usuário a querer e a dever participar da narrativa passando, assim, a conhecer as marcas patrocinadoras e estimulando a compra de seus produtos).

Por isso existe uma triagem, tanto no casting on-line, quanto na postagem nas redes sociais para a realização do filme. Não são todos os vídeos que entram na trama narrativa do filme, nem todos os posts, imagens e outros dados. Temos, assim, um enunciador forte que continua a persuadir o enunciatário, tanto para a realização do filme, quanto para o desenvolvimento da transmídia. Em ambos os casos, prevalece uma manipulação por tentação, uma vez que o enunciador tem poder sobre o texto para manipular o enunciatário a entrar em conjunção com o seu objeto de valor (marca das patrocinadoras Toshiba e Intel) utilizando um objeto de valor de troca (liberdade de Christina). Isso constitui a sintaxe do nível narrativo.

Na semântica do nível narrativo, o fazer-fazer do enunciador-destinador doa valores modais ao enunciatário-destinatário para que ele faça, isto é, compre os produtos das marcas Intel e Toshiba. Para isso, é necessária uma organização modal da competência, tanto do enunciador-destinador, quanto do enunciatário-destinatário. Na

\footnotetext{
${ }^{14}$ Disponível em: https://www.facebook.com/groups/134452603311592/members/ . Acesso em: 31 de mar. 2019.
} 
organização modal da competência do enunciador-destinador, são mobilizadas as modalidades virtualizantes e atualizantes a partir do objeto de valor tecnologia, figurativizado pelo computador, o qual, como já evidenciamos, é o que dá poder ao ator Christina dentro das condições em que se encontra.

Na organização modal da competência do enunciatário-destinatário, também são mobilizadas as modalidades virtualizantes e atualizantes, pois ele tem de querer e dever ajudar Christina a escapar de seu cativeiro. Para isso, deve ter o poder e o saber, que são otimizados, segundo a persuasão contínua e tônica do enunciador-manipulador que está no objeto de valor tecnologia da Toshiba e Intel.

Observando a integração entre as mídias que participaram do projeto Inside nessa campanha, podemos dizer que uma mídia retroalimenta a outra. A seleção das postagens, das imagens e de dados diversos nas redes sociais, e o vídeo vencedor do casting on-line formam, juntos, o filme final, no qual, como último programa de transformação, temos o $S_{1}$ saindo do estado de disjunção com $O v_{1}$ para o estado de conjunção com $\mathrm{Ov}_{1}$. Podemos representar esse programa narrativo final $\left(\mathrm{PN}_{2}\right)$ no seguinte esquema: $\mathrm{PN}_{2}:\left(\mathrm{S}_{2 \text { [ATOR Christina] }} \cup \mathrm{Ov}_{\text {[liberdade] }}\right) \rightarrow\left(\mathrm{S}_{2 \text { [ATOR Christina] }} \cap \mathrm{Ov}_{\text {[liberdade] }}\right)$

Christina, portanto, consegue uma aquisição do $\mathrm{Ov}_{1}$ por doação, uma vez que, ao descobrir com a ajuda de $S_{2}$ o local do cativeiro, ela é libertada. Cumpre-se, assim, a chamada do trailer da campanha publicitária: "A única saída dela será você entrar" (TOSHIBA; INTEL, 2011, tradução nossa) ${ }^{15}$. Em termos semióticos, o ator Christina só entra em conjunção com $\mathrm{Ov}_{1}$ no momento em que o espectador adquire o papel de ator do enunciado, composto pelo componente sintático de adjuvante e o componente semântico das modalidades virtualizantes (querer-fazer; dever-fazer) e atualizantes (poder-fazer; saber-fazer).

\section{Nível discursivo}

No nível das estruturas discursivas, temos as estruturas narrativas enriquecidas semanticamente. Barros (2002, p. 53) explica que "as estruturas narrativas convertem-se em estruturas discursivas quando assumidas pelo sujeito da enunciação. O sujeito da enunciação faz uma série de 'escolhas', de pessoas, de tempo, de espaço, de figuras, e 'conta' ou passa a narrativa, transformando-a em discurso". De acordo com Fiorin

\footnotetext{
${ }^{15}$ Her only way out will be to bring you in inside (original).
} 
(2008b, p. 23), “isso significa que o nível discursivo é, de um lado, o nível da realização do conteúdo manifestado pelo texto; de outro, é responsável pela singularidade dos conteúdos expressos, já que ele não é invariante de outro conteúdo variável [no percurso gerativo do sentido]".

Em Inside - A social film experience, o sujeito da enunciação faz uma série de opções para projetar o efeito de realidade e de proximidade. Embora a enunciação, de todo modo, esteja "filtrando por seus valores e fins tudo o que é dito no discurso" (BARROS, 2002, p. 55), o sujeito da enunciação pode deixar isso menos ou mais explícito. No caso em estudo, o sujeito da enunciação utiliza uma debreagem enunciativa de $2^{\circ}$ grau para instaurar o ator Christina no enunciado. Temos, assim, um $e u$ (figurativizado como Christina), um aqui (figurativizado como um local a ser descoberto) e um agora (temporalizado concomitantemente à sua realização, isto é, ao vivo). Ao optar por delegar voz ao interlocutor, o enunciado torna-se um simulacro da enunciação. Logo, os actantes que falam, o espaço e o próprio tempo simulam os elementos correspondentes da enunciação (eu, aqui, agora). Sendo assim, embora saibamos que o narrador deu a palavra ao interlocutor, que passa a dizer eu e que, portanto, o fato em curso está em um momento diferente do da enunciação, o texto projeta uma ilusão de que está sendo realizado no mesmo instante do ato enunciativo. Eis o efeito de realidade ${ }^{16}$.

Essa é uma enunciação reportada que "corresponde a um simulacro - no interior do discurso - da relação de comunicação entre enunciador e enunciatário" (COURTÉS, 1989, p. 49, tradução nossa) ${ }^{17}$. Como explica Fiorin (2010, p. 40), “a enunciação reportada cria diferentes efeitos de sentido, como objetividade, subjetividade ou realidade [...].”. No caso da campanha em análise, ela cria o efeito de sentido de realidade. Além disso, esse efeito corrobora outro efeito no texto: o de proximidade.

Com a debreagem enunciativa de $2^{\circ}$ grau, o ator Christina relata o seu drama aos seus interlocutários $\left(S_{2}\right)$. Essa narração em primeira pessoa fabrica o efeito de sentido de subjetividade na perspectiva dos fatos vividos que são narrados por quem os viveu ou

\footnotetext{
16 Conforme explica Barros (2008, p. 44), “os simulacros são representações das competências respectivas que se atribuem reciprocamente aos participantes da comunicação e que intervêm como algo prévio, necessário a qualquer relação intersubjetiva. Os simulacros são objetos imaginários que os sujeitos projetam e que, embora não tenham nenhum fundamento intersubjetivo, determinam de maneira eficaz o comportamento dos sujeitos e as relações entre eles".

17 "[...] correspond à un simulacre - à l'intérieur du discours - la relation de communication entre l'énonciateur et l'énonciataire" (COURTÉS, 1989, p. 49, original).
} 
ainda os vivencia. $\mathrm{O}$ discurso em primeira pessoa não fabrica, nesse caso, apenas a ilusão de subjetividade, pois, embora contada em primeira pessoa, a trama de Inside é conduzida por um narrador que ora se identifica com os actantes da narrativa, ora deles se afasta e observa à distância. Por isso, com esse recurso de duas ou mais vozes em diálogo na narração dos fatos (ora é Christina que fala, ora é o narrador, por exemplo), adotam-se perspectivas variadas. Cada perspectiva pode assumir a sua verdade, mas a campanha publicitária, em sua totalidade, consegue relativizar essa dinâmica de vozes: tanto as vozes do texto (por exemplo, Christina e o narrador), quanto as vozes depreendidas do texto (por exemplo, enunciador e enunciatário). Esses elementos constituem a sintaxe do nível discursivo.

Na semântica do nível discursivo, observamos que a campanha publicitária é temático-figurativa. Os percursos temáticos da campanha se configuram pela coerência semântica e a redundância de traços. A começar pela expressão inside, que convoca tematicamente e sinestesicamente o enunciatário a ir para dentro da narrativa, a campanha reitera nos e pelos vários veículos midiáticos que utiliza a necessidade (dever) e o desejo (querer) de participação dos usuários-espectadores. Essa convocação é reforçada pela interação com as postagens no Facebook, selecionadas por Josh Bodnar, e pelo vídeo vencedor do casting on-line. O percurso temático que se instaura a partir dessa participação se constitui ainda pelos seguintes temas: solidariedade, compaixão, liberdade, dentre outros de caráter benevolente. Há, também, temas de caráter malevolente, como o medo e o pânico, os quais são concretizados na figurativização do sequestro de Christina e em seu aprisionamento. Esses temas malevolentes estão muito presentes nas cenas iniciais do filme e no trailer.

A campanha publicitária, por meio desses recursos da sintaxe e da semântica discursivas, conseguiu conquistar o enunciatário satisfatoriamente, haja vista a grande participação do público. Os percursos temáticos de benevolência e de malevolência concretizaram as estruturas narrativas, pois retomaram tanto temas com valor de Bem, quanto temas com valor de Mal. Logo, o investimento temático-figurativo, ao se manifestar, contribuiu para a ilusão de realidade de que o ator Christina era um ser de carne e osso e precisava de ajuda, uma vez que estava vulnerável aos valores de Bem e aos de Mal. Isso, por sua vez, aproxima o enunciador do enunciatário, pois faz do 
enunciado um simulacro da enunciação, nas suas continuidades e descontinuidades, programas e contraprogramas etc.

\section{Nível fundamental}

Nas estruturas fundamentais, encontra-se o mínimo de sentido a partir do qual o discurso se construiu. Escolhemos apresentar as estruturas fundamentais por último em nossa análise, embora esse nível seja o mais simples e abstrato, pois, conforme explica Barros (2002, p. 77), "é mais fácil examinar as estruturas fundamentais depois de apreendidas as organizações narrativas e discursivas do texto".

Nesse nível, compreenderemos o modo de existência da significação como uma estrutura elementar, ou seja, reduziremos a rede de relações que sustentam o texto a uma única relação mínima de sentido. "Compreende-se por quadrado semiótico a representação visual da articulação lógica de uma categoria semântica qualquer" (GREIMAS; COURTÉS, 2008, p. 400). Ao observarmos a relação narrativa recorrente na campanha publicitária entre o ator Christina e o tema tecnologia, este figurativizado como o computador com acesso à internet não rastreável, depreendemos que, sem esse objeto, Christina não poderia ser libertada, pois não teria as modalidades atualizantes (poder-fazer; saber-fazer) que a qualificariam para a interação, no caso, com o sujeitoadjuvante (rede de contatos) e, menos ainda, para a ação, no caso, sair do cativeiro. Se Christina não saísse do cativeiro, ela consequentemente morreria. Logo, a sua vida dependia, direta e indiretamente, de ela possuir ou não as modalidades atualizantes. Como as modalidades atualizantes estão concretizadas na figura do computador, ela precisa utilizá-lo para se manter viva. Eis uma relação que associa Christina ao computador: vida vs. morte.

Outra relação mínima que se estabelece é aquela que diferencia a figura Christina da figura do computador. A figura Christina é da ordem da natureza, isto é, se opõe ao que é artificial ou construído. Como explicam Greimas e Courtés (2008, p. 336-337), natureza constitui “o dado que está aí ou o estado em que se situa o homem desde seu nascimento [...] Nessa perspectiva, natureza não pode ser nunca uma espécie de dado primeiro, original, anterior ao homem, mas uma natureza já 'culturalizada', enformada pela cultura". Por isso, por exemplo, para Christina, é natural usar o computador porque ele faz parte de sua cultura. Logo, o computador é da ordem da cultura e não da natureza, uma vez que pode ocorrer que em determinada cultura o 
computador não seja conhecido ou se tenha dificuldade para utilizar seus recursos. Eis, então, outra relação mínima, a qual diferencia Christina do computador: natureza vs. cultura.

Na campanha publicitária, o enunciador euforizou o eixo da cultura, uma vez que este promovia os valores, as aspirações e as paixões que estimulariam o enunciatário a fazer-fazer, isto é, identificar-se com as marcas Toshiba e Intel e seus produtos. Para isso, como estratégia discursiva e narrativa, o ator do enunciado Christina estava conectado à figura do computador, pois Christina dependia desse objeto para a preservação de sua vida. Desse modo, quanto mais ela estivesse próxima ao eixo da cultura, mais preservaria a sua vida. Na direção contrária, quanto mais se afastasse do eixo da cultura, mais estaria fadada à morte, uma vez que se encontrava sozinha e ninguém conhecia a sua localização. Temos, assim, a articulação entre as duas relações: natureza, morte vs. vida, cultura. Podemos visualizar o quadro semiótico dessas estruturas fundamentais na Figura 3, a seguir:

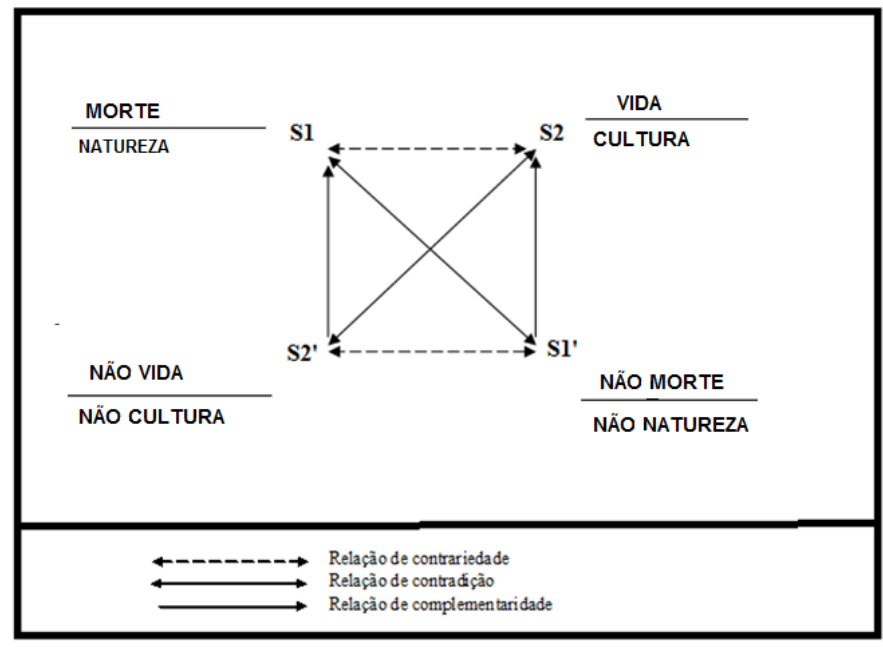

Figura 1. Estruturas fundamentais: morte, natureza vs. cultura, vida. Fonte: Elaboração própria a partir das contribuições de Greimas e Courtés (2008).

Nesse quadrado semiótico, o eixo eufórico pelo sujeito da enunciação no enunciado é o ponto $\mathrm{S} 1$, associando a vida à cultura, que só será possível caso Christina se contraponha antes ao eixo da natureza e da morte ( $\mathrm{S} 1$ ': não natureza; não morte). $\mathrm{O}$ eixo disfórico, por sua vez, é o ponto $\mathrm{S} 2$, relacionando a morte à natureza, que só será possível se Christina renegar primeiro o eixo da cultura e da vida (S2': não cultura; não vida). Essa dinâmica constitui a sintaxe e também a semântica do nível fundamental. 


\section{Considerações finais}

Essa análise semiótica demonstrou o que e como o texto diz a partir da construção textual da campanha e do filme social-interativo, uma vez que recuperamos suas marcas, suas recorrências e suas principais relações de sentido, dos elementos mais concretos e complexos (nível discursivo) aos mais simples e abstratos (nível fundamental). Já o por que o texto diz corresponde às intencionalidades presentes nas escolhas enunciativas de cada texto, o que podemos depreender por meio da relação entre a instância do enunciado e a da enunciação. Essa parte de nossa análise ficou mais saliente quando se discutiu o nível discursivo dessa campanha, no qual destacamos que as escolhas enunciativas do enunciador em interação com o enunciatário se estabeleceram para criar um efeito de sentido de maior realidade e maior proximidade, $\mathrm{o}$ que, estrategicamente, favorece o intercâmbio de valores e, com isso, consegue-se apresentar as potencialidades do produto ao mesmo tempo em que fideliza o usuárioconsumidor.

As projeções teórico-metodológicas que traçamos, como resultados parciais dessa pesquisa em andamento, resultam nas seguintes considerações: primeiramente, as figuras e os temas presentes na organização do texto não são caóticas ou aleatórias. Ao contrário, elas constroem um parecer do sentido, pois, conforme explicam Coelho, Costa e Fontanari (2015, p. 15), “o sentido é um parecer-ser. Ele está sempre inacabado, em constante construção e transformação".

Em segundo lugar, na perspectiva da semiótica discursiva, todo material linguageiro, seja ele extenso ou muito curto, é um texto, desde que tenha sentido. Logo, graças a essa premissa que considera o todo e as partes, pudemos recuperar as marcas discursivas da campanha realizada a partir do filme social-interativo que dela fez parte. Eis a aplicabilidade da teoria semiótica no estudo da transmídia que permite analisar tanto o todo (totalidade da campanha publicitária) como as partes (o filme socialinterativo, o anúncio publicitário, a página de Facebook, dentre outros).

Por fim, conforme Jenkins (2009, p. 343), é preciso teorizar sobre os fenômenos das novas mídias, pois, não raras vezes, "as mídias são interpretadas basicamente como ameaças, em vez de recursos”. Diante desse panorama, a semiótica francesa tem muito a contribuir tanto para a teoria quanto para a análise desses fenômenos. 


\section{Referências}

BARROS, D. L. P. Teoria do discurso: fundamentos semióticos. 3. ed. São Paulo: Editora Humanitas, 2002.

A comunicação humana. In: FIORIN, J. L. (org.) Introdução à linguística: objetos teóricos. 5. ed. São Paulo: Editora Contexto, 2008, p. 25-54.

CAMARA, N. S. Formas de vida no seriado de ficção televisiva Game of Thrones. In: NASCIMENTO, E. M. F. dos S.; ABRIATA, V. L. R. (orgs.). Formas de vida: rotina e acontecimento. Ribeirão Preto-SP: Editora Coruja, 2014, p. 171-192.

COELHO, P. M. F. Novas estratégias publicitárias: games e advergames. Revista Internacional de la Universidad de Sevilla, Servilha, v. I, p. 42-51, 2012.

COELHO, P. M. F.; COSTA, M. R. M.; FONTANARI, R. O parecer do sentido: a perspectiva semiótica. Razón y Palabra, v. 92, p. 1-18, 2015.

COELHO, P. M. F.; COSTA, M. R. M.; MATTAR, J. Saber digital e suas urgências: reflexões sobre imigrantes e nativos digitais Educação e Realidade, Porto Alegre, v. 20, p. 37-51, 2018.

COURTÉS, J. Sémantique de l'énonce: applications pratiques. Paris: Hachette Supérieur, 1989.

DICIONÁRIO DE INFORMÁTICA E NEGÓCIOS - DICWEB. Verbete hotsite. Online. Disponível em: http://www.dicweb.com/hh.htm. Acesso em: 25 nov. 2018.

FIORIN, J. L. Linguagem e interdisciplinaridade. ALEA: Estudos neolatinos. Rio de Janeiro, v. 10, n. 1, p. 29-53, jan./jun. 2008a.

Semiótica e comunicação. In: DINIZ, M. L. V.; PORTELA, J. C. Semiótica e

mídia: textos, práticas, estratégias. Araraquara: UNESP/FAAC, 2008b, p. 77-94.

Astúcias da enunciação: as categorias de pessoa, tempo e espaço. 2. ed. São

Paulo: Editora Ática, 2010.

Semântica estrutural: Pesquisa de método. Tradução de Haquira Osakabe e Izidoro Blikstein. 2. ed. São Paulo: Editora Cultrix, 1976.

GREIMAS, A. J; COURTÉS, J. Dicionário de semiótica. Tradução de Alceu Dias Lima et al. São Paulo: Editora Contexto, 2008.

INTEL BRASIL. Intel e Toshiba lançam o filme colaborativo Inside. Sala de Imprensa Intel Brasil. 15 jul. 2011. Disponível em: http://newsroom.intel.com/community/pt_br/blog/ 2011/07/15/intel-e-toshibalan\%C3\%A7am-o-filme-colaborativo-inside. Acesso em: 25 nov. 2019.

JENKINS, H. Cultura da convergência. Tradução de Susana Alexandria. 2. ed. São Paulo: Editora Aleph, 2009.

LEDO, M. A. Cine documental. Cibercultura, tecnologías de proximidad. Telos: Cuadernos de comunicación e innovación. Logroño. vol. 100, p. 81-83. 2015. Disponível em: http://telos.fundaciontelefonica.com/seccion=1288\&idioma=es_ES\&id=201503171341 0002\&activo=6.do. Acessado em: 31 de mar. 2019.

LIMA, D. de J. L.; MERCADO, L. P. L.; VERSUTI, A. C. A transmídia e sua potência na prática de leitura e produção textual. Revista Ibero-Americana de Estudos em Educação, Araraquara, v. 12, n. esp. 2, p. 1313-1330, ago., 2017. Disponível em:. file://C:/Users/Patricia/Downloads/Dialnet-

ATransmidiaESuaPotenciaNaPraticaDeLeituraEProducao-6202959.pdf. Acessado em: 31 de mar. 2019.

MACIEL, K. Transcinemas. Rio de Janeiro: Contra Capa, 2009. 